\title{
The Dark Tetrad in Tinder: hook-up app for high psychopathy individuals, and a diverse utilitarian tool for Machiavellians?
}

\author{
Minna Lyons ${ }^{1} \cdot$ Ashleigh Messenger $^{1} \cdot$ Rebecca Perry $^{1} \cdot$ Gayle Brewer $^{1}$ \\ Published online: 6 January 2020 \\ (C) The Author(s) 2020
}

\begin{abstract}
Location-based on-line dating applications are a popular tool for initiating short and long-term relationships. Besides seeking for partners, people use these applications for a myriad of other reasons. We investigated how the Dark Tetrad of personality, controlling for sex, age, and trolling tendencies, related to different motives for using Tinder. Current or former Tinder users $(N=216)$ completed online scales for Tinder use motivations, trolling, sadism, and the Dark Triad (Machiavellianism, narcissism, and psychopathy). Using Tinder for acquiring sexual experience was related to being male and being high in psychopathy. Psychopathy was positively correlated with using Tinder to distract oneself from other tasks (e.g., procrastination). Higher Machiavellianism and being female were related to peer pressure as a Tinder use motivation. Using Tinder for acquiring social or flirting skills had a negative relationship with narcissism, and positive relationship with Machiavellianism. Finally, Machiavellianism was also a significant, positive predictor of Tinder use for social approval and to pass the time. Results indicate that individuals high in Machiavellianism use Tinder for a number of utilitarian reasons, whereas the main motive for high psychopathy individuals is hook-up for casual sex.
\end{abstract}

Keywords Dark tetrad $\cdot$ Tinder use $\cdot$ Trolling $\cdot$ Motives

\section{Introduction}

In the past few decades, online dating applications have become a popular tool for initiating contact with romantic and sexual partners. Location-based, real-time applications such as Tinder make it especially easy to impulsively communicate and meet up with others who reside in the same geographical location (Jung et al. 2019). Although Tinder is typically perceived as a casual sex hook-up application (LeFebvre 2018) and, indeed, dates obtained via Tinder often lead to casual sex (Timmermans and Courtois 2018), it is also successfully used for the formation of long-term romantic relationships and platonic friendships (LeFebvre 2018; Timmermans and Courtois 2018). Research has begun to uncover motivations for using Tinder, showing that relationship initiation and hook-up for casual sex are not the only objectives. Indeed, motives for Tinder use

Minna Lyons

m.lyons@liv.ac.uk

1 The University of Liverpool, Bedford Street South, Liverpool L69 7ZA, UK range from thrill seeking, and self-validation to peer pressure, and passing time (Ranzini and Lutz 2017; Sumter et al. 2017; Timmermans and De Caluwé 2017a). These motivations also depend on a host of individual differences, such as age (Sumter et al. 2017), sex (Duncan and March 2019; Ranzini and Lutz 2017), disgust sensitivity (Sevi et al. 2018), and personality (Timmermans and De Caluwé 2017b). Due to the unprecedented popularity of Tinder in the world of online dating and the consequences of such behaviour (Cabecinha et al. 2017), it is important to investigate how individuals differ in their motivations to use the application.

Individual differences are related to motivational drivers, which could influence the reasons for using Tinder. For instance, extraverted people, more prone to needing stimulation, may use Tinder to alleviate boredom, whereas those who are emotionally unstable may use it for boosting self-esteem and seeking for social approval (Orosz et al. 2018; Timmermans and De Caluwé 2017b). Not surprisingly, individuals who have a high socio-sexual orientation (i.e., willingness to engage in casual sex with multiple partners) use Tinder mainly for hooking up for casual sex (Botnen et al. 2018; Sevi et al. 2018). Beyond the Big Five paradigm and basic individual differences (e.g., sex and age), socially malevolent traits such 
as the Dark Tetrad are of special interest in understanding the motivations for using online dating applications (Lyons 2019; Moor and Anderson 2019).

The Dark Tetrad is a constellation of four inter-related, yet distinctive personality traits; Machiavellianism, narcissism, psychopathy, and sadism. At the core of the Dark Tetrad are characteristics such as low empathy and callousness (Book et al. 2016; Međedović and Petrović 2015). The traits have also unique components, such as superiority and a sense of entitlement (narcissism; Raskin and Terry 1988), scheming long-term manipulative strategizing (Machiavellianism; Jones and Paulhus 2009), coldness and anti-social behaviours (psychopathy; Hare 1996), and cruelty and pleasure from hurting others (sadism; Buckels et al. 2013). Of the Big Five traits, the Dark Tetrad is most closely associated with (low) agreeableness, conscientiousness, and emotional stability (Jakobwitz and Egan 2006; Jonason et al. 2013; Kowalski et al. 2019).

Previous research has related Dark Tetrad traits to both relationship preferences and online behaviour. For example, those who score high on Dark Tetrad instruments favour short-term relationships with low levels of commitment (Jonason et al. 2012; Tsoukas and March 2018). This is consistent with research suggesting that for those high in some Dark Tetrad traits (Machiavellianism and psychopathy) casual sex is the primary motivation for using Tinder whilst already in a relationship (Timmermans et al. 2018). The Dark Tetrad traits have been associated with a host of anti-social behaviours in the online environment, including cyberstalking, computer-mediated sexual violence, and sending explicit unsolicited sexual images (Moor and Anderson 2019). Specifically, the Tetrad relates to trolling (Buckels et al. 2014), including trolling when using Tinder (March et al. 2017), as well as to creating conflict in the online dating environment (Duncan and March 2019). Indeed, some users may view Tinder (similar to other online platforms) simply as a forum for trolling. Therefore, it is important to control for the desire to antagonise and bully others (i.e., trolling) when investigating motivations for online Tinder behaviour.

There are other motivations, besides anti-social and sexual behaviour, that could link Tinder use to Dark Tetrad. These have been investigated in a small number of previous studies that have focused on the Dark Triad (i.e., Machiavellianism, narcissism, and psychopathy). For example, Timmermans et al. (2018) found that in non-single Tinder users, social approval was the primary motive for those high in narcissism and Machiavellianism, whereas casual sex was an important driver for those high in psychopathy and Machiavellianism. Further, narcissism was related to using Tinder as a distraction or a tool for entertainment. However, in the growing field of online dating research, the Dark Tetrad has received surprisingly little attention to date.
In the present study, we aim to replicate and extend the findings of Timmermans et al. (2018). First, the replication crisis in psychology is an issue in personality research as well as other areas of psychology. One of the criticisms for the Dark Triad as a specific area of personality psychology has been the lack of replication for existing studies (Lyons 2019). Second, we want to examine the relationship between motivations for Tinder use and the Dark Tetrad by including sadism to the Dark Triad measures. There is relatively little research on sadism and overall mating motivations. Previous studies have found that those high in sadism may use Tinder to satisfy their anti-social needs (Duncan and March 2019), but beyond this, little is known about sadism and dating (see also Foulkes 2019). Third, we wanted to add trolling tendencies as a control variable. Trolling in dating apps is a widespread problem (Thompson 2018), and could be perpetrated especially by those who are high in sadism, psychopathy, and Machiavellianism (Buckels et al. 2014; March et al. 2017). We wanted to add trolling as a control variable in order to investigate how the Dark Tetrad associates with the motivation to use Tinder above and beyond trolling. This study adds to the growing body of literature uncovering how socially malevolent personality traits relate to the use of the cyber environment in facilitating mating goals.

\section{Method}

\section{Participants}

Men $(n=67)$ and women $(n=149)$ aged $18-56$ years $\left(M_{\text {age }}=\right.$ 22.87, $S D=7.09)$ participated in an online survey advertised in online participation forums, the researchers' social networks, and to first year psychology students in exchange for course credit. All participants were current or former Tinder users and the majority of the participants were from the United Kingdom $(n=164)$ or USA and Canada $(n=32)$.

\section{Materials}

For Tinder use, we utilised the Tinder Motives Scale (TMS, Timmermans and De Caluwé 2017a, b). The scale consists of 58, 7-point Likert scale items $(1=$ strongly disagree, $7=$ strongly agree), organised into 13 subscales. Each statement begins "I use Tinder" followed by specific motivations. The 13 subscales are: Social approval (6 items, e.g., "to get compliments", Cronbach's $\alpha=.91$ ); Relationship seeking (5 items, e.g., "to meet a future husband or wife"; $\alpha=.94$ ); Sexual experience (6 items, e.g., "to see how easy it is to find a sex partner"; $\alpha=.91$ ); Flirting/Social skills (6 items, e.g., "to improve my social skills"; $\alpha=.84$ ); Travelling (5 items, e.g., "to meet other travellers/locals when in a foreign country"; $\alpha=.94$ ); Ex (3 items; e.g., "to think less about my ex"; 
$\alpha=.96$ ); Belongingness (4 items, e.g., "to be cool"; $\alpha=.87$ ); Peer pressure (3 items, e.g., "as suggested by friends"; $\alpha=.84$ ); Socializing (4 items, e.g., "to meet new people"; $\alpha=.85$ ); Sexual orientation (3 items, e.g., "to get to know people with the same sexual orientation"; $\alpha=.96$ ); Pass time/Entertainment (7 items, e.g., "because it passes time when I'm bored"; $\alpha=.93$ ); Distraction (3 items, e.g., "to combat boredom when working or studying"; $\alpha=.90$ ); Curiosity (3 items, e.g., "out of curiosity"; $\alpha=.90$ ). Mean scores were calculated for all subscales.

For measuring Machiavellianism, narcissism, and psychopathy, we used the 27-item, 5-point Likert scale (1= strongly disagree, $5=$ strongly agree) Short Dark Triad-3 questionnaire (SD-3, Jones and Paulhus 2014). Nine items are included for each Dark Triad trait. Machiavellianism $(\alpha=.84)$ was measured with statements such as "it's not wise to tell your secrets", narcissism $(\alpha=.75)$ with statements such as "people see me as a natural leader", and psychopathy $(\alpha=.76)$ with statements such as "people often say I'm out of control". Mean scores were calculated for all subscales.

The Short Sadistic Impulse Scale (SSIS, O'Meara et al. 2011) uses 10 items to measure trait sadism in individuals, utilizing a 5 -point Likert scale $(1=$ strongly disagree, $5=$ strongly agree). An example statement is "people would like hurting others if they gave it a go" $(\alpha=.84)$. A mean sadism score was calculated.

The Global Assessment of Internet Trolling (GAIT, Buckels et al. 2014) contains four statements on a 5-point Likert scale ( $1=$ strongly disagree, $5=$ strongly agree $)$ to assess trolling behaviour, identification, and enjoyment in individuals. Examples statements include "I have sent people to shock websites for the lulz", and "The more beautiful and pure a thing is, the more satisfying it is to corrupt" $(\alpha=.75)$. A mean trolling score was calculated.

\section{Results}

In Table 1, we present descriptive statistics and sex differences $(\mathrm{t}$-tests) for all variables measured. Men scored higher than women in using Tinder for sexual motives, and for finding out about sexual orientation. Women scored higher than men in using Tinder to get back at their ex-partner, as well as using it under peer pressure. Men scored higher than women in all of the Dark Tetrad traits, as well as the trolling measure.

Machiavellianism, narcissism, psychopathy, sadism, and trolling were all significantly, positively correlated with each other $(r$ 's $=.18-.54 ; p$ 's <.009). The Pearson's correlations between the Dark Tetrad, trolling, and Tinder motivations are presented in Table 2 (for men), and Table 3 (for women). Generically, the correlations were similar for both sexes between all the Tinder use motivations, and psychopathy and Machiavellianism. Narcissism and the motivation to use
Tinder due to peer pressure was significantly different (Fisher's $z=-2.02, p=.02$ ), revealing a positive relationship in women, and a negative relationship in men. The correlation between sadism and distraction motive were also significantly different between the sexes, indicating that in men (but not in women), sadism correlated positively with distracting oneself (Fisher's $z=2.45, p=.001$ ). Finally, the correlation between sadism and finding about sexual orientation were also different between the sexes, demonstrating a positive correlation in men, but not in women (Fisher's $z=-2.02, p=.02$ ).

In order to investigate the relative influence of the predictor variables on Tinder motivations, we conducted thirteen stepwise multiple regressions with Dark Tetrad traits (narcissism, Machiavellianism, psychopathy, sadism) entered as predictor variables and Tinder use motivations (social approval, relationship seeking, sexual experience, flirting/social skills, travelling, ex, belonging, peer pressure, socializing, sexual orientation, pass time, distraction, and curiosity) as criterion variables. For all analyses, age, sex, and trolling were entered at stage one as control variables; narcissism, Machiavellianism, psychopathy, and sadism were entered at stage two. For social approval, stage one, $F(3,212)=4.86, p=.003, R^{2}=.06$, Adj $R^{2}=.05$, and stage two, $F(7,208)=4.55, p<.001, R^{2}=.13$, Adj $R^{2}=.10$, models were significant. At stage two, age ( $\beta=$ $-.21, t=-3.14, p=.002)$ and Machiavellianism $(\beta=.21, t=$ $2.64, p=.009$ ) were significant individual predictors such that younger participants and those high on Machiavellianism were more likely to use Tinder for social approval.

For sexual experience, stage one, $F(3,212)=18.52$, $p<.001, R^{2}=.21$, Adj $R^{2}=.20$, and stage two, $F(7,208)=$ $14.43, p<.001, R^{2}=.33$, Adj $R^{2}=.30$, models were significant. At stage two, sex $(\beta=-.18, t=-2.88, p=.004)$ and psychopathy $(\beta=.34, t=4.28, p<.001)$ were significant individual predictors such that men and those high on psychopathy were most likely to use Tinder for sexual experience. For flirting/social skills, stage one, $F(3,212)=1.06, p=.367$, $R^{2}=.02$, Adj $R^{2}=.00$, and stage two, $F(7,208)=3.36$, $p=.002, R^{2}=.10$, Adj $R^{2}=.07$, models were nonsignificant and significant respectively. At stage two, narcis$\operatorname{sism}(\beta=-.18, t=-2.34, p=.020)$ and Machiavellianism $(\beta=.32, t=3.93, p<.001)$ were significant individual predictors such that those low on narcissism and high on Machiavellianism were more likely to use Tinder to improve flirting and social skills.

For travelling, stage one, $F(3,212)=4.67, p=.003$, $R^{2}=.06$, Adj $R^{2}=.05$, and stage two, $F(7,208)=3.49$, $p=.001, R^{2}=.10, \operatorname{Adj} R^{2}=.08$, models were significant. At stage two, trolling $(\beta=.19, t=2.23, p=.027)$ and Machiavellianism $(\beta=.17, t=2.04, p=.043)$, with those motivated to troll users and high on Machiavellianism more likely to use Tinder for travelling. With regard to an ex, the stage one, $F(3,212)=2.08, p=.104, R^{2}=.03$, Adj $R^{2}=.02$, and stage two, $F(7,208)=2.18, p=.037, R^{2}=.07$, Adj $R^{2}=.04$, 
Table 1 Descriptive statistics for the Dark Tetrad, trolling, and Tinder motivation

\begin{tabular}{|c|c|c|c|c|c|}
\hline & Mean (SD) & Male mean & Female mean & $t$ & $d$ \\
\hline \multicolumn{6}{|l|}{ Tinder motivations } \\
\hline Social approval & $3.83(1.63)$ & $3.83(1.40)$ & $1.63(1.13)$ & -.01 & 1.73 \\
\hline Relationship seeking & $3.961 .70)$ & $4.03(1.55)$ & $3.93(1.77)$ & .39 & .06 \\
\hline Sexual & $2.89(1.50)$ & $3.71(1.61)$ & $2.50(1.30)$ & $5.85 * *$ & .83 \\
\hline Flirting/Social skills & $3.55(1.38)$ & $3.67(1.32)$ & $3.50(1.40)$ & .83 & .12 \\
\hline Travelling & $2.50(1.55)$ & $1.64(.20)$ & $2.37(1.49)$ & 1.81 & .69 \\
\hline Ex & $3.62(2.01)$ & $3.14(1.85)$ & $3.83(2.05)$ & $-2.36^{*}$ & .35 \\
\hline Belonging & $2.69(1.40)$ & $2.56(1.26)$ & $2.75(1.46)$ & -.90 & .14 \\
\hline Peer pressure & $3.08(1.69)$ & $2.68(1.49)$ & $3.27(1.74)$ & $-2.40^{*}$ & .36 \\
\hline Socializing & $3.76(1.54)$ & $3.86(1.57)$ & $3.71(1.53)$ & .65 & .10 \\
\hline Sexual orientation & $4.32(1.89)$ & $4.76(1.83)$ & $3.71(1.53)$ & $2.30 *$ & .62 \\
\hline Pass time & $4.80(1.40)$ & $4.90(1.28)$ & $4.76(1.46)$ & .72 & .10 \\
\hline Distraction & $3.90(1.81)$ & $3.90(1.68)$ & $3.90(1.87)$ & -.41 & .00 \\
\hline Curiosity & $4.30(1.70)$ & $4.13(1.55)$ & $4.38(1.77)$ & -.94 & .15 \\
\hline \multicolumn{6}{|l|}{ Personality } \\
\hline Machiavellianism & $2.96(.74)$ & $3.20(.73)$ & $2.86(.73)$ & $3.19 * *$ & .47 \\
\hline Narcissism & $2.69(.65)$ & $2.86(.70)$ & $2.61(.62)$ & $2.60 * *$ & .38 \\
\hline Psychopathy & $2.19(.66)$ & $2.53(.67)$ & $2.04(.60)$ & $5.34 * *$ & .77 \\
\hline Sadism & $1.77(.85)$ & $2.21(1.16)$ & $1.58(.58)$ & $5.30 * *$ & .69 \\
\hline Trolling & $1.75(1.00)$ & $2.30(1.29)$ & $1.51(.72)$ & $5.75 * *$ & .76 \\
\hline
\end{tabular}

models were not significant and significant respectively. At stage two, $\operatorname{sex}(\beta=.19, t=2.60, p=.010)$ was the only significant individual predictor, with women more likely to cite an ex as motivation for Tinder use.

For peer-pressure, stage one, $F(3,212)=3.87, p=.010$, $R^{2}=.05$, Adj $R^{2}=.04$, and stage two, $F(7,208)=2.86$, $p=.007, R^{2}=.09, \operatorname{Adj} R^{2}=.06$, models were significant. At stage two, $\operatorname{sex}(\beta=.20, t=2.71, p=.007)$ and Machiavellianism $(\beta=.22, t=2.69, p=.008)$ were the only significant predictors, with women and those high on Machiavellianism more likely to use Tinder as a consequence of peer-pressure. For passing time / entertainment, stage one, $F(3,212)=2.52, p=.059, R^{2}=.03$, Adj $R^{2}=.02$, and stage two, $F(7,208)=3.56, p=.001, R^{2}=.11$, Adj $R^{2}=.08$, models were not significant and significant respectively. At stage two, Machiavellianism $(\beta=.23, t=2.84, p=.005)$ was the only significant predictor, such that those high on Machiavellianism were more likely to use Tinder to pass the time or for entertainment. For distraction, stage one, $F$ (3, $212)=1.76, p=.156, R^{2}=.02, \operatorname{Adj} R^{2}=.01$, and stage two, $F(7,208)=3.33, p=.002, R^{2}=.10$, Adj $R^{2}=.07$, models were not significant and significant respectively. At stage two, psychopathy $(\beta=.25, t=2.70, p=.008)$ was the only significant predictor, such that those high on psychopathy were more likely to use Tinder as a form of distraction.

The models for relationship seeking (stage one, $F$ (3, $212)=2.15, p=.095$; stage two, $F(7,208)=1.16, p=.326)$, belonging (stage one, $F(3,212)=1.44, p=.232$; stage two, $F$ $(7,208)=2.04, p=.052)$, socialising (stage one, $F(3$, $212)=.27, p=.848$; stage two $F(7,208)=.93, p=.487)$, sexual orientation (stage one, $F(3,212)=2.02, p=.112$; stage two, $F(7,208)=2.04, p=.052$ ), and curiosity (stage one, $F$ $(3,212)=1.46, p=.227$; stage two, $F(7,208)=1.94$, $p=.065)$, were not significant.

\section{Discussion}

Our results suggest that darker aspects of personality are related to unique motivations for using a real-time, locationbased dating application. Sadism did not predict Tinder use motivations, suggesting that Dark Triad rather than the Dark Tetrad is significant for this online behaviour. For psychopathy, we replicated the findings of Timmermans et al. (2018), showing that those high in psychopathy were more likely to use Tinder to gain sexual experience. The high sex drive and short-term mating orientation associated with psychopathy (e.g., Book et al. 2016) clearly translates into using online dating applications for sexual gratification. Other significant finding with regard to psychopathy was the use of Tinder for distracting oneself from other tasks. Previous research has found that especially the impulsive secondary psychopathy facet is related to procrastination in order to avoid completing other tasks (Lyons and Rice 2014). Perhaps high psychopathy 
Table 2 Pearson's Rank correlation coefficients for the Dark Tetrad, trolling, and Tinder motivations in men $(n=67)$

\begin{tabular}{|c|c|c|c|c|c|}
\hline & Machiavellianism & Narcissism & Psychopathy & Sadism & Trolling \\
\hline Social approval & $.24 *$ & $.24 *$ & .19 & .24 & .20 \\
\hline Relationship seeking & .04 & -.09 & -.09 & -.09 & -.12 \\
\hline Sexual experience & $.36^{* *}$ & $.28^{* *}$ & $.53 * *$ & $.35 * *$ & $.43 * *$ \\
\hline Flirting/Social skills & .14 & -.07 & -.05 & .02 & -.01 \\
\hline Travelling & .19 & .07 & .18 & .07 & .02 \\
\hline Ex & .15 & .14 & .21 & .16 & .06 \\
\hline Belonging & .15 & .15 & .17 & .06 & $.25^{*}$ \\
\hline Peer pressure & .17 & -.13 & -.08 & .04 & .10 \\
\hline Socializing & .14 & .01 & .06 & .06 & .12 \\
\hline Sexual orientation & $.25^{*}$ & .19 & $.30^{*}$ & .20 & .17 \\
\hline Pass time & .14 & $.27^{*}$ & .13 & .19 & .18 \\
\hline Distraction & $.30 *$ & .18 & $.33 * *$ & $.36 * *$ & $.25^{*}$ \\
\hline Curiosity & .05 & -.11 & -.01 & -.07 & .14 \\
\hline
\end{tabular}

$* p<.05 * * p<.01$ individuals procrastinate by focussing on tasks that are more intrinsically motivating, such as finding short-term sexual partners online. The associations between psychopathy, and distraction and sexual experience motivations are interesting, and could have links with the overall impulsive, hedonistic, and procrastinating lifestyles of high psychopathy individuals.

The long-term strategic and flexible nature of Machiavellianism (Jones and Paulhus 2009) was evident in the Tinder use motivations. Machiavellianism had a positive relationship with using Tinder for social approval (i.e., to get validation from others about one's attractiveness), when travelling, as a consequence of peer-pressure, to pass time or provide entertainment, and to practise social skills and flirting. All motivations could reflect the use of social and online environment to reach long-term objectives (Bereczkei 2018). For instance, Machiavellianism has been associated with the use of social media for self-presentation (Abell and Brewer 2014) and impression management tactics (Hart et al. 2019). Our findings extend self-presentation to the dating environment. Using Tinder for social approval and conforming to peer pressure could all be part of a façade that makes Machiavellian individuals more socially desirable partners.

The relationship between Machiavellianism and the use of Tinder to pass time or provide entertainment is consistent with a recent study that failed to find a connection between Machiavellianism and a wide range of movie and music preferences (Bowes et al. 2018). It is possible that Machiavellian individuals have a more utilitarian approach to their entertainment and use tools that also provide real-life benefits (e.g., acquisition of a partner). Additional research is required to explore Machiavellianism and this aspect of human behaviour.

Narcissism predicted the use of Tinder to improve flirting and social skills only. Those high on narcissism display a sense of superiority and entitlement (Emmons 1984), for example believing themselves to be more desirable than their romantic partners (Campbell et al. 2002). The relationship between narcissism and this motivation may, therefore, reflect the tendency of high narcissist's to believe that they already excel in this field and do not need to develop their flirting or social skills.

This study has some limitations. For example, participants who did not conform to a binary gender identify were not represented in the sample, nor did we ascertain the sexual orientation or relationship status of participants. Sexual orientation is likely to influence the motivation of finding out information about sexual orientation of others but is unlikely to have an impact on other Tinder motives (Timmermans and De Caluwé 2017b). Around 15-20\% of Tinder users report being in a committed relationship (Orosz et al. 2018; Timmermans and De Caluwé 2017b), but it is currently not clear how the motivations of individuals with different levels of Dark Tetrad 
Table 3 Pearson's Rank correlation coefficients for the Dark Tetrad, trolling, and Tinder motivations in women $(n=149)$

\begin{tabular}{|c|c|c|c|c|c|}
\hline & Machiavellianism & Narcissism & Psychopathy & Sadism & Trolling \\
\hline Social approval & $.29 * *$ & .10 & $.25^{* *}$ & .15 & .01 \\
\hline Relationship seeking & & -.03 & -.02 & .09 & -.10 \\
\hline Sexual experience & $.19 *$ & $.22 * *$ & $.40 * *$ & $.24 * *$ & .15 \\
\hline Flirting/Social skills & $.27 * *$ & -.04 & .14 & .02 & -.06 \\
\hline Travelling & $.24 * *$ & $.19^{*}$ & $.22 * *$ & $.21 * *$ & $.18 *$ \\
\hline Ex & .15 & -.03 & .13 & -.03 & -.07 \\
\hline Belonging & $.21 *$ & .13 & .12 & -.03 & .01 \\
\hline Peer pressure & $.21 *$ & $.17^{*}$ & .10 & .04 & .06 \\
\hline Socializing & .14 & .02 & .12 & .14 & -.06 \\
\hline Sexual orientation & .13 & .10 & .10 & -.06 & -.02 \\
\hline Pass time & $.33^{* *}$ & .14 & $.23 * *$ & -.01 & .02 \\
\hline Distraction & $.17^{*}$ & .11 & $.24 * *$ & .01 & -.09 \\
\hline Curiosity & $.19 *$ & .07 & .01 & -.11 & -.07 \\
\hline
\end{tabular}

$* p<.05 * * p<.01$

may be influenced by their relationship status. This is certainly something that future research should take into consideration.

In addition, it is important to note that current findings are reliant on the honesty and accuracy of participant responses to self-report questionnaires. Socially desirable responding is positively related to narcissism and negatively related to Machiavellianism and psychopathy (Kowalski et al. 2018). In order to counteract this, future research should include objective measures of Tinder activity rather than rely only on self-reports. Also, our study included a short Dark Triad measure, which fails to capture the multidimensionality of the construct, and provides a weak differentiation between psychopathy and Machiavellianism (Miller et al. 2019). The study would benefit from replication with longer measures, which would allow investigations into how different components of the Dark Triad relate to on-line dating motivations.

Finally, it is unclear what real-life implications the Tinder use motivations have. Do high psychopathy individuals successfully acquire sexual partners on Tinder? Does Tinder use influence the status, likeability, or social influence of individuals high on Machiavellianism? The present study is hopefully a starting point for investigating whether the Dark Tetrad relates to Tinder use motivations because these motivations lead to some form of social or sexual success.

In summary, we investigated the relationship between socially malevolent personality traits, and the motivations to use a popular real-time, location-based dating application, Tinder.
Beyond the identity and enjoyment in trolling, sadism may have little relationship with Tinder use motivations. Those high in psychopathy were motivated by sexual experience and distraction. As a testimony to the flexibility of Machiavellianism as a trait, we found that it correlated with a myriad of reasons not directly associated with short-term sexual hook-ups. Online dating may, therefore, provide an opportunity to develop skills that of use in future situations, something that long-term strategists (i.e., high Machiavellian individuals) may be oriented to.

\section{Compliance with Ethical Standards}

Conflict of Interest On behalf of all authors, the corresponding author states that there is no conflict of interest.

Ethical Statement (Including the Name of the Approval Board) All procedures performed in studies involving human participants were in accordance with the ethical standards of the institutional and/or national research committee (Psychology ethics committee, reference 3603) and with the 1964 Helsinki declaration and its later amendments or comparable ethical standards.

Informed Consent Informed consent was obtained from all individual participants included in the study.

Open Access This article is licensed under a Creative Commons Attribution 4.0 International License, which permits use, sharing, adaptation, distribution and reproduction in any medium or format, as long as you give appropriate credit to the original author(s) and the source, 
provide a link to the Creative Commons licence, and indicate if changes were made. The images or other third party material in this article are included in the article's Creative Commons licence, unless indicated otherwise in a credit line to the material. If material is not included in the article's Creative Commons licence and your intended use is not permitted by statutory regulation or exceeds the permitted use, you will need to obtain permission directly from the copyright holder. To view a copy of this licence, visit http://creativecommons.org/licenses/by/4.0/.

\section{References}

Abell, L., \& Brewer, G. (2014). Machiavellianism, self-monitoring, selfpromotion and relational aggression on Facebook. Computers in Human Behavior, 36, 258-262. https://doi.org/10.1016/j.chb.2014. 03.076 .

Bereczkei, T. (2018). Machiavellian intelligence hypothesis revisited: What evolved cognitive and social skills may underlie human manipulation. Evolutionary Behavioral Sciences, 12(1), 32-51. https:// doi.org/10.1037/ebs0000096.

Book, A., Visser, B. A., Blais, J., Hosker-Field, A., Methot-Jones, T., Gauthier, N. Y., et al. (2016). Unpacking more "evil": What is at the core of the dark tetrad? Personality and Individual Differences, 90, 269-272. https://doi.org/10.1016/j.paid.2015.11.009.

Botnen, E. O., Bendixen, M., Grøntvedt, T. V., \& Kennair, L. E. O. (2018). Individual differences in sociosexuality predict picturebased mobile dating app use. Personality and Individual Differences, 131, 67-73. https://doi.org/10.1016/j.paid.2018.04. 021 .

Bowes, S. M., Watts, A. L., Costello, T. H., Murphy, B. A., \& Lilienfeld, S. O. (2018). Psychopathy and entertainment preferences: Clarifying the role of abnormal and normal personality in music and movie interests. Personality and Individual Differences, 129, 33-37. https://doi.org/10.1016/j.paid.2018.03.009.

Buckels, E. E., Jones, D. N., \& Paulhus, D. L. (2013). Behavioral confirmation of everyday sadism. Psychological Science, 24(11), 22012209. https://doi.org/10.1177/0956797613490749.

Buckels, E. E., Trapnell, P. D., \& Paulhus, D. L. (2014). Trolls just want to have fun. Personality and Individual Differences, 67, 97-102. https://doi.org/10.1016/j.paid.2014.01.016.

Cabecinha, M., Mercer, C. H., Gravningen, K., Aicken, C., Jones, K. G., Tanton, C., et al. (2017). Finding sexual partners online: Prevalence and associations with sexual behaviour, STI diagnoses and other sexual health outcomes in the British population. Sexually Transmitted Infections, 93(8), 572-582. https://doi.org/10.1136/ sextrans-2016-052994.

Campbell, W. K., Rudich, E. A., \& Sedikides, C. (2002). Narcissism, selfesteem, and the positivity of self-views: Two portraits of self-love. Personality and Social Psychology Bulletin, 28(3), 358-368. https:// doi.org/10.1177/0146167202286007.

Duncan, Z., \& March, E. (2019). Using tinder® to start a fire: Predicting antisocial use of tinder ${ }^{\circledR}$ with gender and the dark tetrad. Personality and Individual Differences, 145, 9-14. https://doi.org/10.1016/j. paid.2019.03.014.

Emmons, R. A. (1984). Factor analysis and construct validity of the narcissistic personality inventory. Journal of Personality Assessment, 48(3), 291-300. https://doi.org/10.1207/ s15327752jpa4803_11.

Foulkes, L. (2019). Sadism: Review of an elusive construct. Personality and Individual Differences, 151, 109500.

Hare, R. D. (1996). Psychopathy: A clinical construct whose time has come. Criminal Justice and Behavior, 23(1), 25-54. https://doi.org/ 10.1177/0093854896023001004.
Hart, W., Breeden, C. J., \& Richardson, K. (2019). Differentiating dark personalities on impression management. Personality and Individual Differences, 147, 58-62. https://doi.org/10.1016/j.paid. 2019.04.030.

Jakobwitz, S., \& Egan, V. (2006). The dark triad and normal personality traits. Personality and Individual Differences, 40, 331-339. https:// doi.org/10.1016/j.paid.2005.07.006.

Jonason, P. K., Luevano, V. X., \& Adams, H. M. (2012). How the Dark Triad traits predict relationship choices. Personality and Individual Differences, 53(3), 180-184. https://doi.org/10.1016/j.paid.2012.03. 007.

Jonason, P. K., Kaufman, S. B., Webster, G. D., \& Geher, G. (2013). What lies beneath the Dark Triad dirty dozen: Varied relations with the Big Five. Individual Differences Research, 11(2), 81-90.

Jones, D. N., \& Paulhus, D. L. (2009). Machiavellianism. In M. R. Leary \& R. H. Hoyle (Eds.), Handbook of individual differences in social behavior (pp. 93-108). New York: Guilford Press.

Jones, D. N., \& Paulhus, D. L. (2014). Introducing the short dark triad (SD3): A brief measure of dark personality traits. Assessment, 21(1), 28-41. https://doi.org/10.1177/1073191113514105.

Jung, J., Bapna, R., Ramaprasad, J., \& Umyarov, A. (2019). Love unshackled: Identifying the effect of mobile app adoption in online dating. MIS Quarterly, 43, 47-72.

Kowalski, C. M., Rogoza, R., Vernon, P. A., \& Schermer, J. A. (2018). The Dark Triad and the self-presentation variables of socially desirable responding and self-monitoring. Personality and Individual Differences, 120, 234-237. https://doi.org/10.1016/j.paid.2017.09. 007.

Kowalski, C. M., Di Pierro, R., Plouffe, R. A., Rogoza, R., \& Saklofske, D. H. (2019). Enthusiastic acts of evil: The assessment of sadistic personality in polish and Italian populations. Journal of Personality Assessment, 1-11.

LeFebvre, L. E. (2018). Swiping me off my feet: Explicating relationship initiation on tinder. Journal of Social and Personal Relationships, 35(9), 1205-1229. https://doi.org/10.1177/0265407517706419.

Lyons, M. (2019). The dark triad of personality: Narcissism, Machiavellianism, and psychopathy in everyday life. Academic Press.

Lyons, M., \& Rice, H. (2014). Thieves of time? Procrastination and the Dark Triad of personality. Personality and Individual Differences, 61, 34-37. https://doi.org/10.1016/j.paid.2014.01.002.

March, E., Grieve, R., Marrington, J., \& Jonason, P. K. (2017). Trolling on Tinder ${ }^{\circledR}$ (and other dating apps): Examining the role of the Dark Tetrad and impulsivity. Personality and Individual Differences, 110, 139-143. https://doi.org/10.1016/j.paid.2017.01.025.

Međedović, J., \& Petrović, B. (2015). The dark tetrad: Structural properties and location in the personality space. Journal of Individual Differences, 36, 228-236. https://doi.org/10.1027/1614-0001/ a000179.

Miller, J. D., Vize, C., Crowe, M. L., \& Lynam, D. R. (2019). A critical appraisal of the Dark-Triad literature and suggestions for moving forward. Current Directions in Psychological Science. https://doi. org/10.1177/0963721419838233.

Moor, L., \& Anderson, J. R. (2019). A systematic literature review of the relationship between dark personality traits and antisocial online behaviours. Personality and Individual Differences, 144, 40-55. https://doi.org/10.1016/j.paid.2019.02.027.

O'Meara, A., Davies, J., \& Hammond, S. (2011). The psychometric properties and utility of the short sadistic impulse scale (SSIS). Psychological Assessment, 23(2), 523-531. https://doi.org/10. 1037/a0022400.

Orosz, G., Benyó, M., Berkes, B., Nikoletti, E., Gál, É., Tóth-Király, I., \& Böthe, B. (2018). The personality, motivational, and need-based background of problematic Tinder use. Journal of Behavioral Addictions, 7(2), 301-316. https://doi.org/10.1556/2006.7.2018.21. 
Ranzini, G., \& Lutz, C. (2017). Love at first swipe? Explaining Tinder self-presentation and motives. Mobile Media \& Communication, 5(1), 80-101. https://doi.org/10.1177/2050157916664559.

Raskin, R., \& Terry, H. (1988). A principal-components analysis of the narcissistic personality inventory and further evidence of its construct validity. Journal of Personality and Social Psychology, 54(5), 890-902.

Sevi, B., Aral, T., \& Eskenazi, T. (2018). Exploring the hook-up app: Low sexual disgust and high sociosexuality predict motivation to use Tinder for casual sex. Personality and Individual Differences, 133, 17-20. https://doi.org/10.1016/j.paid.2017.04.053.

Sumter, S. R., Vandenbosch, L., \& Ligtenberg, L. (2017). Love me Tinder: Untangling emerging adults' motivations for using the dating application Tinder. Telematics and Informatics, 34(1), 67-78. https://doi.org/10.1016/j.tele.2016.04.009.

Thompson, L. (2018). "I can be your Tinder nightmare": Harassment and misogyny in the online sexual marketplace. Feminism \& Psychology, 28, 69-89. https://doi.org/10.1177/ 0959353517720226.

Timmermans, E., \& Courtois, C. (2018). From swiping to casual sex and/ or committed relationships: Exploring the experiences of Tinder users. The Information Society, 34(2), 59-70. https://doi.org/10. 1080/01972243.2017.1414093.

Timmermans, E., \& De Caluwé, E. (2017a). Development and validation of the Tinder Motives Scale (TMS). Computers in Human Behavior, 70, 341-350. https://doi.org/10.1016/j.chb.2017.01.028.

Timmermans, E., \& De Caluwé, E. (2017b). To Tinder or not to Tinder, that's the question: An individual differences perspective to Tinder use and motives. Personality and Individual Differences, 110, 74 79. https://doi.org/10.1016/j.paid.2017.01.026.

Timmermans, E., De Caluwé, E., \& Alexopoulos, C. (2018). Why are you cheating on tinder? Exploring users' motives and (dark) personality traits. Computers in Human Behavior, 89, 129-139. https://doi. org/10.1016/j.chb.2018.07.040.

Tsoukas, A., \& March, E. (2018). Predicting short-and long-term mating orientations: The role of sex and the dark tetrad. The Journal of Sex Research, 55(9), 1206-1218. https://doi.org/10.1080/00224499. 2017.1420750.

Publisher's Note Springer Nature remains neutral with regard to jurisdictional claims in published maps and institutional affiliations. 